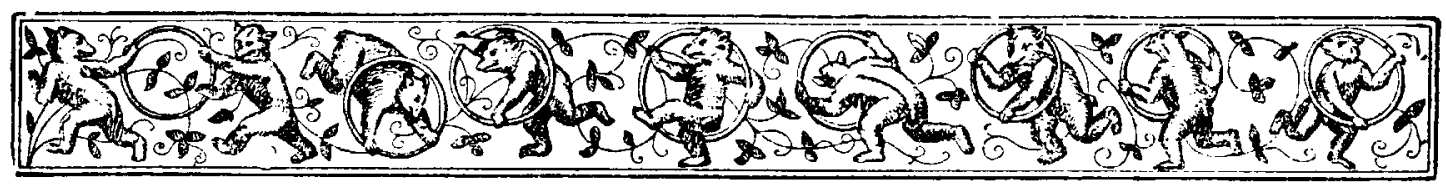

\title{
EEN PORTET VAN JACOB VAN CAMPEN DOOR FRANS HALS
}

DOOR

\author{
DR. C. HOFSTEDE DE GROOT.
}

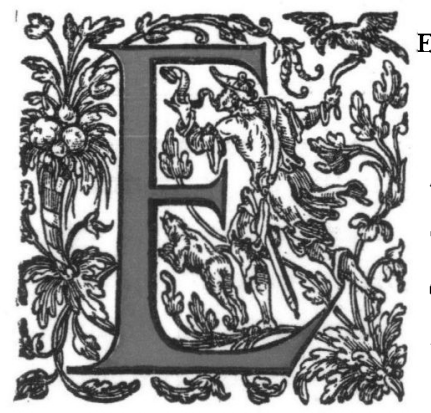

ENIGE jaren geleden herkende ik in het legaat LAVALARD $D E$ ROYE in het Museum te Amiens het portret van Herman Langelius, door Frans Hals, welks bestaan tot dusver alleen door den prent van ABRAHAM BLOOTELING bekend was. Bij die gelegenheid vond ik ook dat er naast dit en een tweede op naam van FRANS HALS staand portret nog een derde hing op naam van den jongen FraNs HaLS, doch eveneens door den vader geschilderd. Wien dit portret voorstelde, zag ik evenwel eerst, toen kort geleden het fraaie prachtwerk der Heeren BINDER en BODE verscheen, waarin alle werken van den meester zijn afgebeeld. Immers uit eene vergelijking met het portret van JACOB VAN CAMfEN in het boek over het Amsterdamsche Stadhuis, dat in I66 I bij DANCKER DANCKERTSZ. voor de eerste maal verscheen, bleek zonneklaar, dat niemand anders dan onze beroemde bouwmeester hier was geconterfeit.

Ook het portret in zwart krijt in het Amsterdamsche Prentenkabinet, dat het monogram van JAN LIEvENS draagt en daarom aan dezen meester wordt toegekend, vertoont geheel en al dezelfde trekken. Het schijnt de moeite waard te trachten de onderlinge verhouding van deze drie portretten vast te stellen.

Het portret door HALS is een borstbeeld ongeveer tot aan de maagstreek zonder handen of armen en met een hoed op het weelderige haar. De onbekende graveur daarentegen vertoont den haardos zonder hoed en geeft van het lichaam 


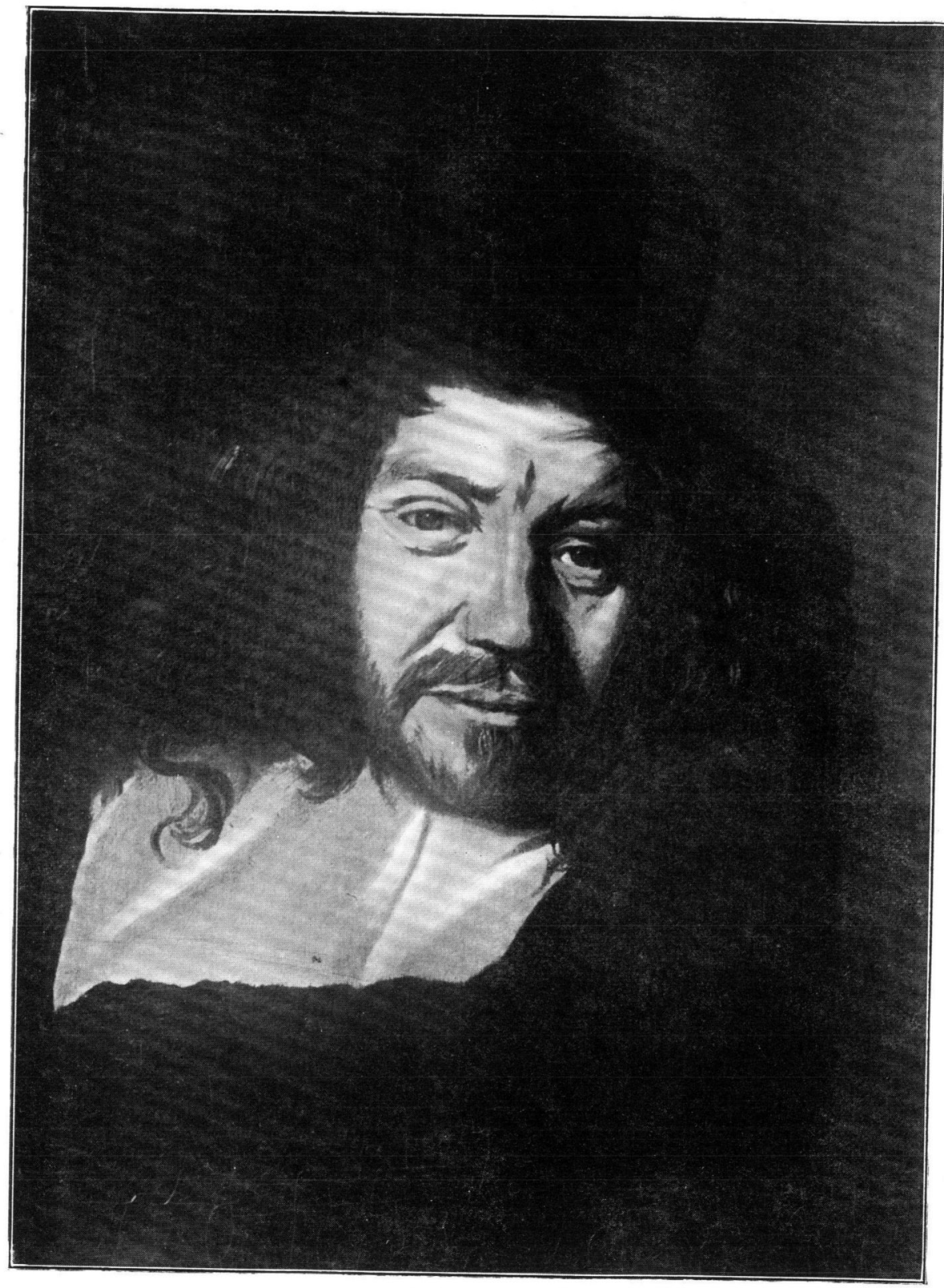

Jacob van Campen.

Schilderij van Frans Hals in het Museum te Amiens.

(Naar eene photographie van de Photographische Gesellschaft te Berlijn). 
het geheele bovenlijt - wel is waar grootendeels verborgen achter een stuk zerken muur - en den geheelen rechter arm, die op het stuk muur rust. De prent is een spiegelbeeld van het schilderij.

De teekening is in dezelfde richting als het schilderij genomen. VAN CAMPEN draagt evenals op 't schilderij een hoed. Van het lichaam en den eenen arm is even veel te zien als op de prent. Het zerken stuk muur vertoont, even aangeduid, een laag verheven bloemslinger en een geprofileerden plint. De achtergrond bestaat rechts uit een muur en een ronde zuil op een hoog voetstuk met een opgenomen lap doek met twee kwasten. Links in de verte is het Amsterdamsche Stadhuis vluchtig aangeduid.

Met het schilderij heeft de teekening den hoed, met de prent de verdere aanduiding van het lichaam gemeen. Op zich zelf staat $z i j$, wat de versiering van het brokstuk muur en de toevoeging van een achtergrond betreft.

Het meest authentieke portret is het gesnedene, dat van den naam van den voorgestelde voorzien is en van een lofgedicht van zijn tijdgenoot LuDovicus Meyer, een Amsterdamsch geneesheer, taalkundige en wijsgeer. Het komt voor in de door DANCKER DANCKERTSz bezorgde uitgave van het Amsterdamsche stadhuis, die in $166 \mathrm{I}$, dus slechts vier jaren na vaN CAMPENS overlijden, voor het eerst verscheen. Dat het portret van HALS eveneens vaN CAMPEN voorstelt, kan aan geen twijfel onderhevig zijn en ik meen zelfs te durven aannemen, dat het tijdens VAN CAMPENS leven is geschilderd. Het past, wat de uitvoering betreft, zeer goed bij de werken van HALS van omstreeks I655 (Vergelijk bijv. het portret van TyMAN OOSDORP te Berlijn van 1656 ). Ook meen ik voor zeker te durven houden, dat de onbekende plaatsnijder het geschilderde portret tot voorbeeld heeft genomen, al heeft hij bijv. de aanduiding van den korten bakkenbaard weggelaten. Daartegenover staat immers, dat andere kleinigheden, zooals de bovenloop van de snor en de onregelmatige slagschaduw van den neus zoo in 't oog loopend overeenkomen, dat aan toeval te dien opzichte niet te denken is.

Dit aangenomen blijft de vraag: wat moeten wij denken van de teekening met de beginletters van JaN Lievensz? Heeft deze naar het schilderij van HaLS gewerkt en heeft de graveur hem tot voorbeeld genomen in die bijzonderheden, die hij meer heeft dan FRANS HaLS? Dit zou men moeten veronderstellen, zoolang men aan JAN LIEvENS als maker der teekening hecht, daar men van een kunstenaar van zijn rang niet kan aannemen, dat hij voor een dergelijk portret een schilderij en een prent van twee verschillende kunstenaars als voorbeelden van noode zou gehad hebben.

Houdt men daarentegen niet aan den naam van LIEVENS voor de teekening vast, en beschouwt men dus het monogram als valsch, dan wordt de teekeOud-Holland, ig15. 
ning het werk van eenen onbekende, die de beide voorbeelden te zijner beschikking had en met behulp daarvan zijn produkt vervaardigde.

Wij trachten dus de vraag te beantwoorden: is de Amsterdamsche teekening werkelijk wel het werk van LIEvens?

$\mathrm{Zij}_{\mathrm{ij}}$ is er voor doorgegaan sinds de veiling $\mathrm{J}$. DE BOSCH van 5 Oct. 1767 , waarin ik haar voor 't eerst aantrof. Later was $z i j$ in de beroemde kabinetten van C. Ploos van Amstel (1800), J. de Vos Sen. (1833), J. G. Verstolk VAN SOELEN (I847) en J. DE VOS Jun. (I883). Op laatstgenoemde veiling werd zij door het Rijk aangekocht.

$Z \mathrm{ij}$ heeft dus een stamboom als de beste en toch geloof $\mathrm{ik}$, dat haar faam meer hierop berust, dan op haar innerlijke artistieke eigenschappen. Het best vergelijkt men haar met het schilderij om te doen uitkomen, hoeveel zwakker zij is. Het kloek aangegeven schedelstelsel, dat men door het vleezige gelaat van HALs' model henen ziet, is geheel verdwenen, de blik uit de oogen is verwazigd, de welving van het voorhoofd vervlakt. De krachtig geteekende mond op het schilderij is tot een slappe lijn geworden! Hoe anders ziet een echte LiEvens er uit, zooals het fraaie portret van JAN VOS in het Städel'sche Instituut. Ook de plooien van den mantel, de behandeling van mouw, kraag, manschet en handschoen staan in geenen deele op de hoogte van den meester en de versiering van het blok steen, die de teekenaar aanbracht, is al even kinderachtig gedaan als de zuil en de draperien van den achtergrond, om van het Stadhuis maar in 't geheel niet te spreken.

Het sterkst bewijs tegen LIEVENS en in 't algemeen tegen den titel van kunstenaar voor den vervaardiger dezer teekening is de houding der linker en toevoeging der rechter hand. De linkerhand rust op de prent ongedwongen op en hangt even over den bovenkant van den steen, aan den pols even ondersteund door de zware aanhangsels van den leeren handschoen. Op de teekening daarentegen, rust de elleboog op den steen en steunt de hand op duim en pink terwijl da wijsvinger loshangt en de twee middelste over den rand afhangen. Men trachte eens deze houding na te bootsen en dan gelijktijdig de door den teekenaar aangeduide rechter hand tegen den zijkant van den steen te leggen. Op zich zelf is dit reeds bezwaarlijk, om niet te zeggen onmogelijk, maar het is dit in ieder geval in verband met de houding van den rechter arm, die onder den mantel verborgen is. Volgens deze moet de rechterhand ongeveer op de knie liggen.

Bij zulke in 't oog loopende gebreken, moet ik aannnemen dat het monogram valsch en de teekening niet van LiEvENS is, doch van een der talrijke vervaardigers van valsche portretten uit het midden der XVIIIe eeuw, die voor zijn falsifikaat zoowel de prent als het schilderij te zijner beschikking heeft gehad. 


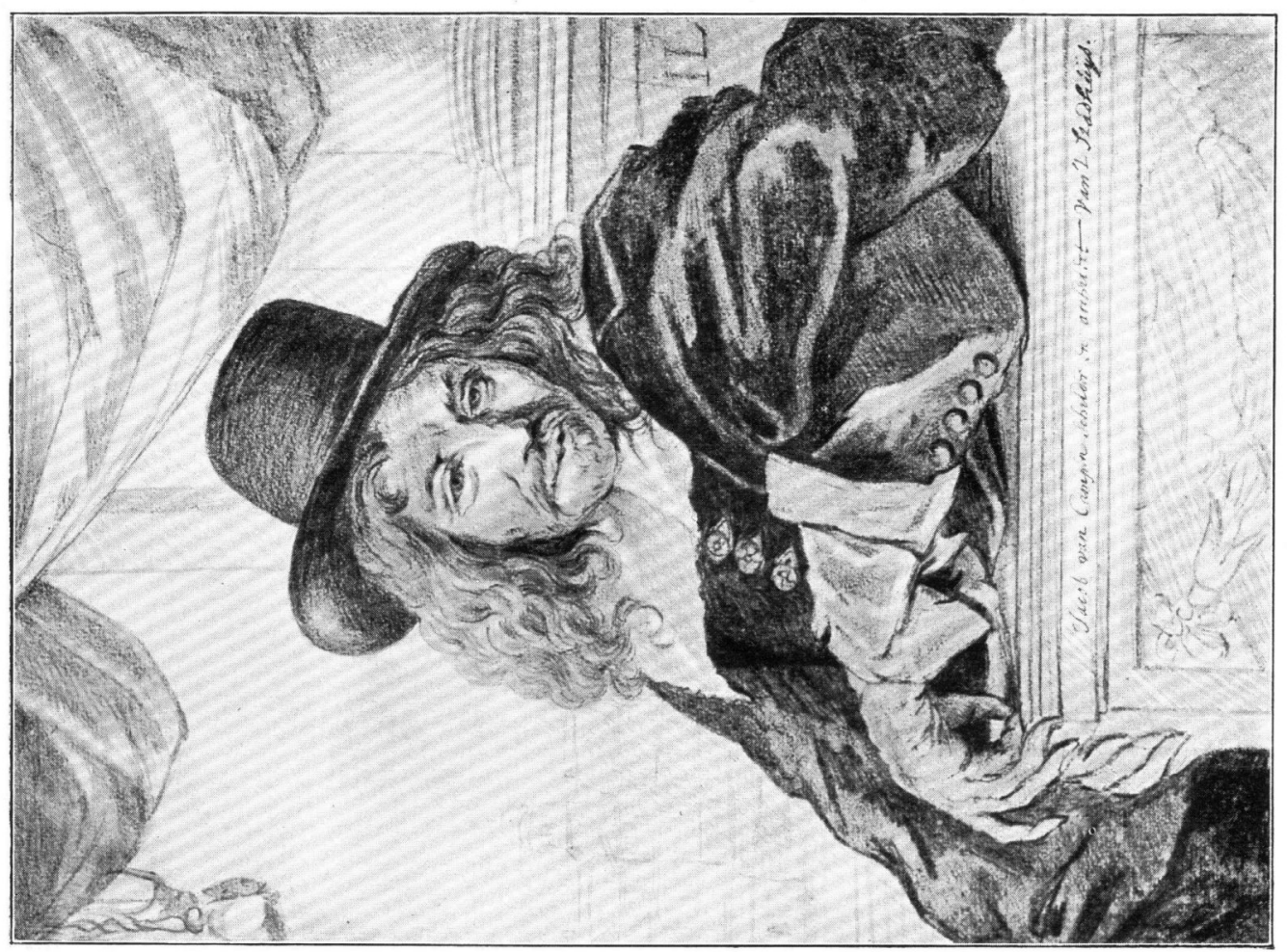

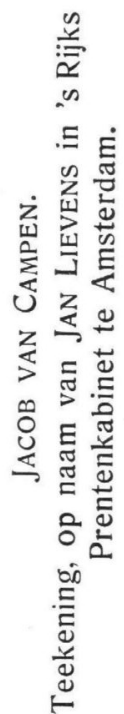

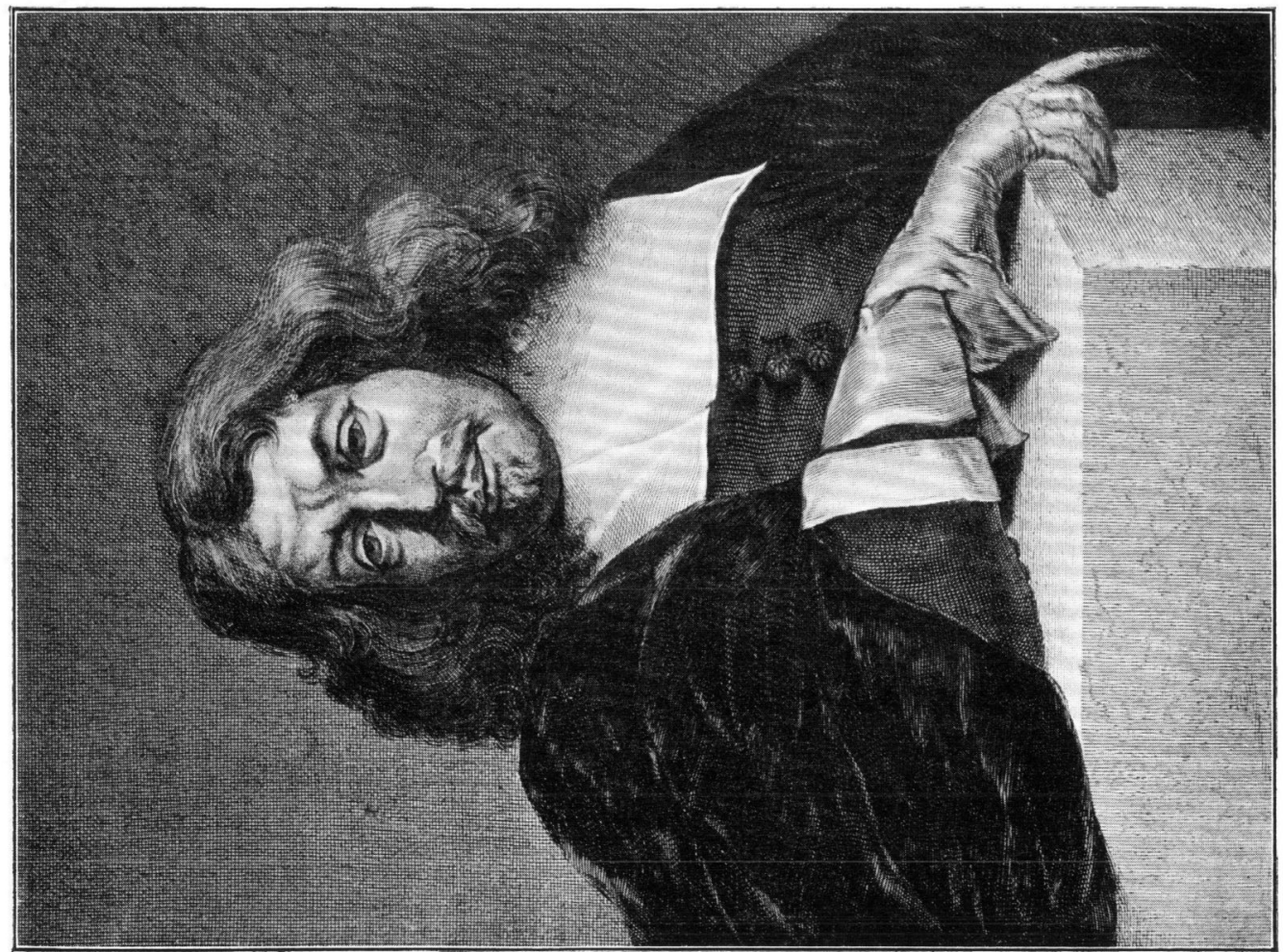

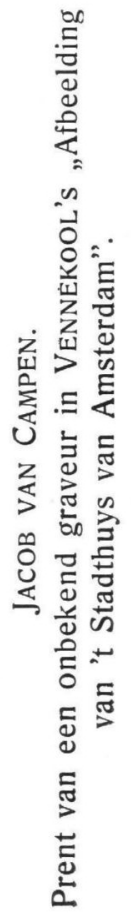

